\title{
Correlation between Receptive Metaphoric Competence and Reading Proficiency
}

\author{
Qian Zhao ${ }^{1}$, Liang $\mathrm{Yu}^{2} \&$ Yanqing Yang ${ }^{3}$ \\ ${ }^{1}$ Department of Foreign Languages, Chongqing College of Humanities, Science \& Technology, Chongqing, \\ China \\ ${ }^{2}$ School of Computer and Information Science, Southwest University, Chongqing, China \\ ${ }^{3}$ Online and Continuing Education College, Southwest University, Chongqing, China \\ Correspondence: Qian Zhao, Chongqing College of Humanities, Science \& Technology, Chongqing, China. Tel: \\ 023-6836-7393. E-mail: jullyzq1225@hotmail.com
}

Received: July 28, 2014 Accepted: September 10, 2014 Online Published: October 23, 2014

doi:10.5539/elt.v7n11p168 URL: http://dx.doi.org/10.5539/elt.v7n11p168

\begin{abstract}
Metaphoric competence is an essential part of language concept fluency and communicative competence.Since metaphor is pervasive in language, when Chinese second language (L2) learners are engaged in reading process, one of the barriers to influence their comprehension is metaphor. This paper aims to empirically investigate the relationship between the receptive metaphoric competence and reading proficiency of Chinese learners of English, in order to arouse Chinese English teachers' attention to metaphor instruction. The results show that the two are significantly correlated, however, the metaphoric competence of English learners in China is ranked middle or low, and the L2 learners who are skilled at L2 reading are more inclined to be at a higher level of metaphoric competence.
\end{abstract}

Keywords: metaphor, receptive metaphorical competence, reading proficiency, correlation

\section{Introduction}

\subsection{Introduction of Metaphoric Competence}

Since Aristotle's "Rhetoric" was initiated more than two thousand years ago, the study on metaphor has experienced overwhelming and radical developments and changes. The point that deserves attention is that the dividing line between the classic view and the modem one is the position they hold on the identity of metaphor. The classic view represented by Aristotle holds that literal language is true and primary while metaphor is a matter of words, rather than a thought and metaphoric language lies outside ordinary, everyday language. Nevertheless, the modern view, represented by Lakoff and Johnson (1980), proposes that metaphor is pervasive in daily life, not just in language but in thought and action, and our ordinary conceptual system is fundamentally metaphoric in nature (Lakoff \& Johnson, 1980). Similar to Chomsky's linguistic competence and Hymes' communicative competence, Pollio and Smith (1980) for the first time put forward the concept of metaphoric competence (MC) (Pollio \& Smith, 1980). Furthermore, some scholars developed the definition of MC step by step. In her recent study, Jeannette Littlemore (2001a) elaborates MC from the following four aspects: originality of metaphorical production; fluency ofmetaphor interpretation; ability to find meaning in metaphor; and speed in finding meaning in metaphor (Littlemore, 2001a). Then Azuma (2005) generalizes MC as the composition of receptive metaphoric competence (R-MC) and productive metaphoric competence (P-MC) (Azuma, 2005).

However, although the research findings about metaphor both home and abroad are so fruitful, the application of metaphor to second language acquisition (SLA hereafter) is far from demanded. According to Azuma (2005), one of the reasons might be due to the low accessibility of the target language (Azuma, 2005), and another one might be that the significance of metaphor instruction in the classroom has not gained enough attention.

Reading comprehension, whether in first or second language acquisition, is a very complex mental process in which the reader uses his mentality to obtain meaning from written material. As Richards (1965) points out, in the area of English as foreign language (EFL hereafter) teaching and learning, the communicative methodology has derived attention and development, one of which is to make EFL learners totally immersed in the foreign or second language environment. Subsequently, it is natural for the learners to get in touch with more and more 
authentic target language materials (including reading material) that certainly contain a large number of English metaphoric expressions. We cannot get through three sentences of fluid discourse without it (metaphor) (Richards, 1965). It can be inferred that at least to some extent the metaphoric competence of an EFL learner can influence or even determine his reading proficiency.

Moreover, some metaphors influence the understanding of reading due to the conceptual features of metaphor. On the lexical level, some conventional metaphorical mappings prompt to infer new derivative metaphors which are important in reading. For example, according to the conceptual metaphor INTERNET IS A HIGHWAY, it is easy to draw the meanings of phrases, such as information highway, cyber space, cyber tourism, cyber surfer, etc. On the discoural level, some metaphors benefit the learners to grasp the main ideas and macro-structure of the text in a top-down pattern. For instance, if the text is about competition in business, the conceptual metaphors and the corresponding mapping structures, such as BUSINESS IS A WAR, can be applied into the whole text. Therefore, the two parties of the business competition can attack, defend, dominate, yield or abandon their market in as fighting manner. In this way, the text can be easily expected and concluded in a macro way.

It is known that the performance in tests can play an effective role as feedback. So if it can be verified the positive or significant correlation between learners' MC and their corresponding performance in the language tests, both the teachers and learners are more likely to pay attention to metaphoric instruction and learning in future time.

\subsection{Related Studies on Metaphorical Competence}

Since metaphor is pervasive in everyday language, the ability to comprehend and produce metaphor is quite important to the learning of a language. This ability, according to Gardner and Winner, is named metaphorical competence, a term analogous to Chomsky's linguistic competence. With the development of the studies on metaphor, language researchers are paying more and more attention to the studies of metaphorical competence.

Gardener and Winner (1979) defined metaphorical competence as:

The capacity to paraphrase a metaphor, to explain the rationale for the metaphor's effectiveness, to produce a metaphor appropriate to a given context, to evaluate the appropriateness of several metaphoric expressions (Gardener \& Winner, 1979).

By doing experiments with a developmental methodology, which is based on Piaget's developmental epistemology, they did three studies on metaphorical competence: the development of metaphorical comprehension, the development of metaphorical production and the breakdown of metaphorical capacities on the part of aphasiacs. The experiment results show that metaphorical competence is one of the key factors to constitute human's cognitive and linguistic ability.

Similar study on the development of metaphorical comprehension was done by Ortony (1980a, 1980b). The results show that children, even the youngest ones, showed a clear preference for meaningful comparisons over anomalous ones, although the older children did better at rejecting anomalous comparisons than the younger children and that none of the groups selected literal or metaphorical completions significantly more than chance. They did not show obvious preference for either metaphorical or literal.

In a recent article on metaphorical language and second language teaching, Marcel Danesi (1992) discussed one potential source of the failure to teach the utilization and comprehension of metaphoric language in elementary and intermediate Italian courses (Danesi, 1992). Danesi reported on a pilot study conducted at the University of Toronto in 1991. The tentative results of this research project show that non-native speakers of Italian were much less successful than their native-speaker counterparts in interpreting and translating metaphors in Italian. In that same article, Danesi (1992) also reported on comparable results for a similar study carried out with students enrolled in a Spainish program (Danesi, 1992).

Low (1988) made a pioneering examination of metaphorical competence. He broke down a "metaphorical competence" into such elements as "the ability to construct plausible meanings, to differentiate between new metaphors, conventional metaphors and idiosyncratic extensions of old ones". He further saw it as incorporating an awareness of how to avoid the coinage of absurd metaphors and an understanding of the "hedges" which signal whether a statement is to be interpreted metaphorically or not (Low, 1988).

Metaphor research comparing native with non-native languages (e.g. English) for educational purposes has abounded more in the occidental than in the oriental world. This is due to the degree to which learners are exposed to metaphors in the target languages and their levels of language proficiency. In an ESL situation, where learners live in the environment of using a target language (take English in this study for example), exposure is high and intensive, and consequently linguistic level is high. In an EFL situation, learners, accessibility to 
English is limited, therefore, their level of English proficiency vary from low to high. However, in both situations, adequate understanding and use of metaphoric expressions are desirable language competences for learners to enable understanding of delicate and subtle nuances of expressions in English.

Generally, there are previously two kinds of researches on metaphoric competence: one is on awareness (Boers, 2000; Deignan, Gabrys, \& Solska, 1997) and the other is on competence itself (Johnson \& Rosano, 1993; Littlemore, 2001b; Low, 1988). Surveys on awareness and competence are not completely separable, because surveys on awareness also examine competence. The majority of the researches on metaphoric competence in the occidental world have been carried out with children (Cameron, 2003; Gardener, 1974) and with ESL learners (Littlemore, 2001b). Statistical data on competence was prepared only by Littlemore (Littlemore, 2001b).

According to Cameron and Low (1999), all learners of English as a second language need to develop at least some metaphor-related skills (Cameron \& Low, 1999). He advises us to know that learning "one-off" examples is not always helpful. He discusses approaches and areas in which learners should develop some skills related to metaphor (e.g. the ability to interpret and construct plausible meanings by using metaphor, knowledge of the boundary metaphor and awareness of some features of metaphor), and proposes activities for language lessons. Deignan, Gabrys, and Solska (1997), further emphasize the importance of dealing with metaphors in language lessons (Deignan, Gabrys, \& Solska, 1997). They experiment on the cross-linguistic awareness-raising activities to aid understanding of English metaphoric expressions using Polish as L1 and English as L2 and claim that the same conceptual metaphors in different languages are realized through different linguistic expressions, concluding that L2 learners usually find it difficult to use metaphors appropriately.

Littlemorediscusses a number of psychological processes involving metaphor interpretation and examines metaphoric competence and its relationship to L2 learning and teaching (Littlemore, 2001b). Metaphoric competence, according to Littlemore, consists of (a) originality of metaphor production, (b) fluency of metaphor interpretation, (c) ability to find meaning in metaphor and (d) speed in finding meaning in metaphor. She examined whether or not metaphoric competence is a unitary concept, identified cognitive traits that may help it develop, and investigated its relationship with communicative language ability. Apparently the first item (a) proposed by Littlemore is typed into production and the other three to recognition. Items (b), (c) and (d) relate to finding the meanings of metaphoric expressions, while item (a) relates to producing metaphors on one's own. The latter may be one of the most difficult tasks for EFL students to accomplish in the field of metaphor study.

Based on Littlemore's classification of metaphoric competence, Azuma (2005) proposed metaphoric competence is mainly composed of receptive metaphoric competence (R-MC in short, i.e. understanding the concepts of English metaphors and the concepts behind English metaphorical expressions), productivemetaphoric competence (P-MC in short, i.e. use of English metaphorical expressions in appropriate ways) and learners' recognition in listening and reading metaphorical expressions) (Azuma, 2005). In her research to investigate the factors that influence metaphoric competence, she used the receptive metaphoric competence (R-MC hereafter) test, productive metaphoric competence (P-MC hereafter) test as well as XY-test (to mainly test testees' metaphorical sensibility) to examine the subjects' metaphoric competence.

\section{The Research}

\subsection{Aims of the Research}

This paper aims to examine the correlation between metaphoric competence and reading proficiency. From the literal perspective, Harmer (2003) argues that as a receptive skill, one component of metaphoric competence- $\mathrm{R}-\mathrm{MC}$, is more intimately related to reading proficiency than P-MC (Harmer, 2003), for the former two both involve the decoding of language symbols and interpretation. Therefore this paper will adopt Azuma's test of R-MC to the more elaborate study.

To be more specific, the main purpose of the research is to empirically investigate the relationship between receptive metaphoric competence and reading proficiency.

\subsection{Participants}

The sample of this investigation includes 80 students from the school of foreign languages, Southwest University, who are all freshmen and receive this test at the end of their first year, most of whom are aged between 18and 20. They are selected casually by the computer according to their student number. However, the computer selection has been done separately to males and female to guarantee the sufficient number of male subjects' participation because of the serious gender imbalance in the school of foreign languages. They include 65 female and 15 male volunteers, because of the imbalance between two genders in the school. All these students are recruited into the 
university in the year 2006. All the testees are native speakers of Chinese, learning English as a foreign language All passed the entrance examination to college and their English proficiency scores in this exam are nearly all over 120 (the full score is 150). In other words, these freshmen's English proficiency has reached a certain level so that they are supposed to deal with some metaphoric problems in learning foreign language.

\subsection{Instruments}

The research instruments are divided into two tests, namely, the one for R-MC test and the other for reading proficiency test.

The R-MC test is originated from Mazumi Azuma's (2005) test for metaphoric competence (Azuma, 2005). The author of this paper adapted some testing items in order to fit the subjects' English proficiency. Considering the reliability, we adopted the split-half method to examine the internal consistency of our test. We grouped all the odd-numbered items into the first half and all the even-numbered items into the second half. The reliability coefficient obtained by correlating the scores of the odd statements with the scores of the even statements is .639 $(\mathrm{p}=.000$, significant at the .01 level). According to the Spearman-Brown prophecy formula, the reliability of the original test is .7729 (equal length). The reliability was therefore considered to be sufficiently high for the purpose of the current research.

The receptive metaphoric competence test is composed of two parts. The first part is called XY-test (MC-XYT hereafter), and the second part is called Receptive-test (MC-RT hereafter).

The MC-XYT is designed to test the subjects' metaphorical sensibility and skills. This test originated in Winner, Rosenstiel, and Gardner (1976), who used the sentence pattern of An X is an adjective Y, in which X and Y are nouns in their experiment. The same sentence pattern is employed in this study and examinees are asked to write two sentences using the target adjective embedding into them: one employed is literal and the other has a metaphoric meaning (Winner, Rosenstiel, \& Gardner, 1976). This also aims to measure polysemy and metaphoric skills, using the combination of adjective and nouns. The five adjectives, which mostly belong to high frequency levels, are selected for this test. They were bright, dark, grey, high and weak and wild. Therefore, the subjects are required to write two sentences for each adjective using the pattern $\mathrm{An} \mathrm{X}$ is an adjective $\mathrm{Y}$.

According to Azuma (2005), the criteria for the XY-T lie on that each answer which makes sense in a literal sentence and which showed a reasonable mapping from the "source" (vehicle) and the "target" (topic) in a metaphoric sentence is rated as one point each: one point for a literal meaning and one point for a metaphoric meaning (Azuma, 2005). A half-point score is permitted if a sentence runs well in a literal and/or a metaphoric sense but there is ambiguity between a target-source linkage or if it does not follow the required format. The following first examples are the answers rated as one point for a literal use and one point for a metaphoric use, and the second are rated as a half point for literal and metaphoric use respectively.

An example of a student's answer which obtained one point:

Target adjective: bright

Literal: At night this street is a bright street.

Metaphoric: Her eyes arebright jewels.

An example of a student's which obtained a half point:

Target adjective: grey

Literal: My father's hair is grey.

Metaphoric: I have a grey life.

The second part of metaphoric competence test is MC-RT. The author adapts the testing items from Azuma as well. Originally, the combination of RT is inspired by Gibbs' (1980) experiments on understanding and memory for idioms. He uses eight stories with "literal" target sentences and eight stories with "idiomatic" target sentences (Gibbs, 1980). In addition to testing purposes, this kind of reading exercise may be especially useful for EFL students as it helps them understand that the same expression conveys different implications in different contexts. Each idiom or expression chosen is one written in easy English in order to minimize EFL students' anxiety, despite this, it is still rich in context, and it is such that it could be used in both physical and psychological meanings, that is, lexically easy but slightly complicated in the sense of psychological and/or cultural implication (see Appendix for complete proofs).

The subjects are required to write two pairs of meaning for each idiom or expression, one containing literal meaning and the other metaphoric implication. A correct and clear interpretation of a meaning or implication is 
allocated three points; an answer which is judged correct but which included some ambiguity two points; an answer which stops explanation halfway but is correct up to that point is allocated one point; an incorrect or no answer received zero points. Students are allowed to answer in the native language (here Chinese) to exclude the language ambiguity in their answering. According to Azuma (2005), Table 1 summarizes the criteria used for scoring RT (Azuma, 2005).

Table 1. Criteria for interpretation of a metaphoric passage

\begin{tabular}{ll}
\hline Scores & Criteria for interpretation of a metaphoric passage \\
\hline 3 & The meaning of the target expression is interpreted correctly. \\
2 & The interpretation of the target expression can be judged correct, but the answer includes \\
& some ambiguity in interpretation or lacking detail or precision. \\
0 & The answer is too brief to judge precisely correct or incorrect; incomplete interpretation. \\
\hline
\end{tabular}

All the papers were collected by the author herself and the answers of MC test were judged by two native speakers of English (both are visiting scholars in Southwest University) in order to avoid inaccuracy.

As for the reading proficiency test, the author decides to adopt the reading proportion of the final examination of comprehensive English for freshmen, in order to improve efficiency and effectiveness. This final examining paper is carefully designed by the English teachers and professors in the school of foreign languages, Southwest University, China. By several years' practice, this paper proves to be an efficient one to test learners' English proficiency. In addition, the adoption of this paper does not cost the subjects' spare time and it is an important exam for them, so the students are supposed to take it seriously and the validity of the test can be thus guaranteed. The reading test in this paper is composed of two parts, namely, cloze and reading comprehension.

\subsection{Research Questions and Hypotheses}

The paper aims to answer the following questions:

1) How do receptive metaphoric competence and reading comprehension proficiency correlate with each other?

2) How do the two testing items and receptive metaphoric competence correlatewith each other?

3) How dothe two testing items of receptive metaphoric competence respectively relate to reading proficiency?

Therefore, based on the previous questions, the following 3 hypotheses are proposed:

Hypopaper 1. The total scores of receptive metaphoric competence and scores of reading comprehension proficiency are correlated with each other.

Hypopaper 2. Scores of MC-XY-T (one part of metaphoric competence test) are correlated with scores of MC-R-T (the other part of metaphoric competence test).

Hypopaper 3. Scores of MC-XY-T and MC-R-T are respectively related to scores of reading test.

\subsection{Procedures}

The procedures are composed of two stages, namely, the pilot test and the main test. The pilot test was undertaken one week before the main test was put into practice in order to get rid of the ambiguities in the instruction. Ten freshman testees were asked to finish the receptive metaphoric test in 30 minutes, with detailed instructional information provided by the author. After the testing, we interviewed some of the testees and questioned about their feeling towards this test. Furthermore, the answers were analyzed and some adjustments were made to make this test more successful and to guarantee its validity and reliability.

Then the main test was carried out. The reading proficiency test was taken at the end of the testees' first schooling year, as part of the final exam of the course "comprehensive English". The reading test included two section-cloze and reading comprehension tests. The receptive metaphoric test was taken half a month before the final exam in order to guarantee the validity of the test. The testees were told the importance of the metaphoric test, and 80 testees voluntarily took part in the test. Nearly all the testees did the test in a rather easy state. They were also warned against the loss of points caused by the random guessing. Eventually 75 testing papers, among all the 80 papers, were collected to be valid and the rest were invalid because of the loss of testees' names (the missing of names resulted in no finding of the corresponding scores of reading test) and several unqualified papers. 
All the data collected were put into the computer for statistical analysis. The software utilized to process the data was the SPSS.

\section{Statistical Analysis and Discussion}

\subsection{Descriptive Data}

This paper aims to study the correlation between receptive metaphoric competence and reading proficiency, so the data of those two will be illustrated firstly.

We will first take an analysis of the data of the total scores for reading proficiency, which include cloze and reading comprehension.

For the 75 cases in this test, presented in the following Table 2 are these data.

Table 2. Scores of reading proficiency

\begin{tabular}{|c|c|c|c|c|}
\hline \multicolumn{5}{|c|}{ Descriptives } \\
\hline & & & Statistic & Std. Error \\
\hline \multirow[t]{13}{*}{ Reading } & Mean & & 30.20 & .475 \\
\hline & $95 \%$ confidence & Lower bound & 29.25 & \\
\hline & Interval for mean & Upper bound & 31.15 & \\
\hline & $5 \%$ trimmed mean & & 30.25 & \\
\hline & Median & & 30.00 & \\
\hline & Variance & & 16.892 & \\
\hline & Std. Deviation & & 4.110 & \\
\hline & Minimum & & 21 & \\
\hline & Maximum & & 38 & \\
\hline & Range & & 17 & \\
\hline & Interquartile range & & 7 & \\
\hline & Skewness & & -.266 & .277 \\
\hline & Kurtosis & & -.685 & .548 \\
\hline
\end{tabular}

We can find from the previous description that nearly all the subjects, scores are ranked between 21 to 38 . Their scores show a central tendency. We can see it more clearly from the following Figure 1.

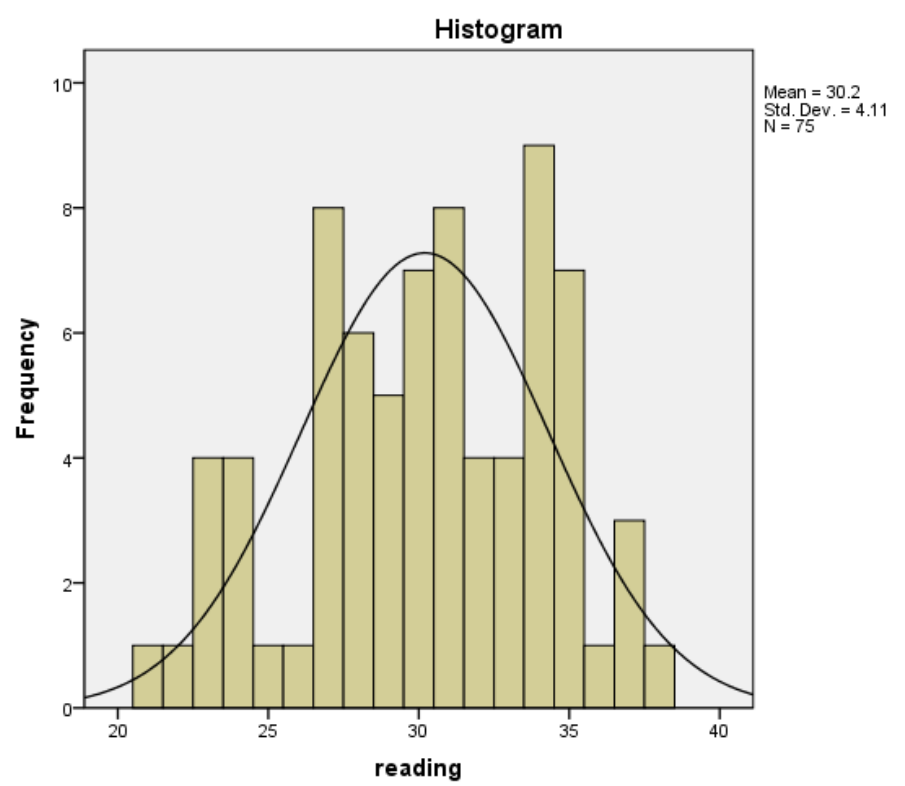

Figure 1. Histogram of the scores of reading proficiency 
Then we will describe the data of scores for receptive metaphoric competence, which include MC-XY-T and MC-R-T, shown in Table 3 and Figure 2.

Table 3. Scores of receptive metaphoric competence

\begin{tabular}{|c|c|c|c|c|}
\hline \multicolumn{5}{|l|}{ Descriptives } \\
\hline & & & Statistic & Std. Error \\
\hline \multirow[t]{13}{*}{ MC-XY-R } & Mean & & 30.187 & 1.0088 \\
\hline & $95 \%$ confidence & Lower bound & 28.177 & \\
\hline & Interval for mean & Upper bound & 32.197 & \\
\hline & $5 \%$ trimmed mean & & 30.730 & \\
\hline & Median & & 31.000 & \\
\hline & Variance & & 76.330 & \\
\hline & Std. Deviation & & 8.7367 & \\
\hline & Minimum & & 1.5 & \\
\hline & Maximum & & 44.5 & \\
\hline & Range & & 43.0 & \\
\hline & Interquartile range & & 11.0 & \\
\hline & Skewness & & -.950 & .277 \\
\hline & Kurtosis & & 1.205 & .548 \\
\hline
\end{tabular}

From the previous description we know that most of the testees' scores are located between 20 and 40 . A few of them did a rather good job. We will also see it more clearly from the following chart. However, their MC-XT-T scores are not ranked high, which illustrates their metaphoric sensibility or skills is not very high.

We are informed from the chart that the average score of the testees are neither high nor low, which show the level of their receptive metaphoric competence arrives at some degree. It is more clearly shown in Figure 2.

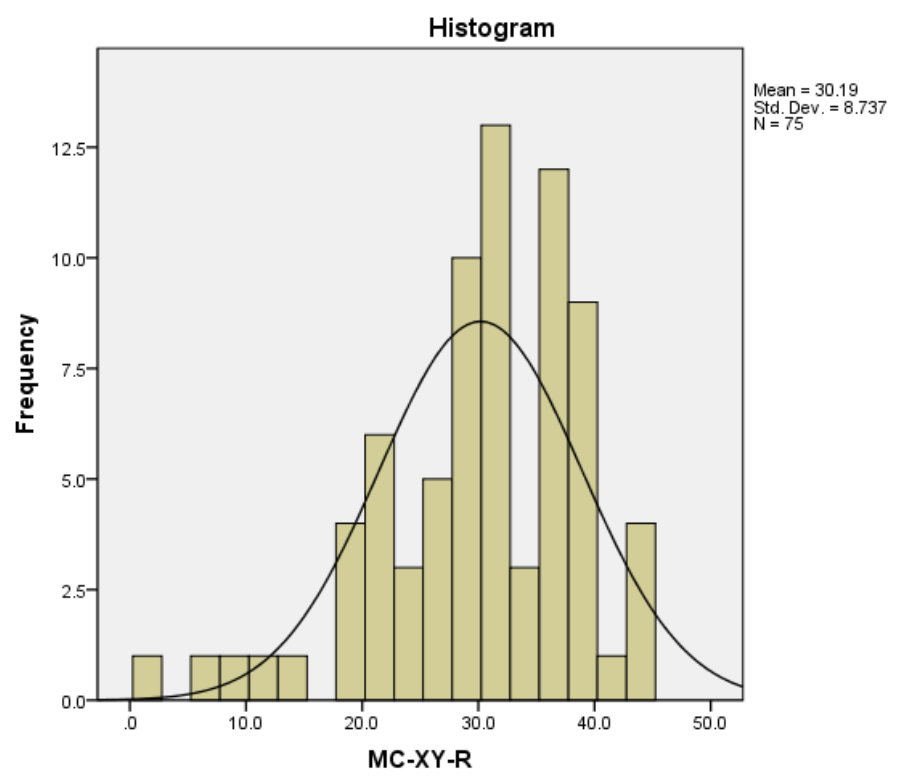

Figure 2. Histogram of the scores of receptive metaphoric competence

\subsection{Discussion of Research Hypotheses}

The most important issue this paper intends to examine is the relationship between receptive metaphoric competence and reading proficiency. We have mentioned before that scores on R-MC test and scores on reading test respectively represent the level of these two. Meanwhile, as both the L2 proficiency test scores and the 
receptive metaphoric competence scores are not normally distributed, it is not possible for us to use the Pearson product-moment correlation coefficient to measure their correlation. We turn to the Spearman rank correlation coefficient, which is often used to measure nonparametric correlation.

Some points need to mention in order to employ the output more clearly:

1) +1 stands for perfect positive correlation and -1 is perfect negative correlation, so the value of the correlation fluctuates within this range.

2) $1 \%$ level or $5 \%$ level is merely varying degrees of significant correlation and coefficient at $1 \%$ level is stronger than that at 5\% level.

Below is Table 4 produced by SPSS.

Table 4. Correlation between reading and MC-XY-R

\begin{tabular}{lllll}
\hline & & Reading & MC-XY-R \\
\hline Spearman's rho & Reading & Correlation Coefficient & 1.000 & $.428^{* *}$ \\
& & Sig. (2-tailed) &. & .000 \\
& N & 75 & 75 \\
& MC-XY-R & Correlation Coefficient & $.428^{* *}$ & 1.000 \\
& Sig. (2-tailed) & .000 &. \\
& $\mathrm{~N}$ & 75 & 75
\end{tabular}

Note. $* *$ Correlation is significant at the 0.01 level (2-tailed).

From the computational result, the significance of correlation between scores of reading proficiency and receptive metaphoric competence is .001 , which proves the correlation between receptive metaphoric competence and reading proficiency. In addition, the correlation coefficient $\mathrm{p}$ is .428 . According toConnollyand Sluckin (1953)'s criteria (Connolly \& Sluckin, 1953), we conclude that the scores of receptive metaphoric competence and reading proficiency are significantly correlated. Consequently it verifies our first hypopaper that the total scores of receptive metaphorical competence and reading proficiency are correlated with each other.

Now we will examine the second hypopaper. Below is the computational result produced by SPSS shown in Table 5 .

Table 5. Correlations between MC-XY and MC-R

\begin{tabular}{lllll}
\hline & & MC-XY & MC-R \\
\hline Spearman's rho & MC-XY & Correlation Coefficient & 1.000 & $.269^{*}$ \\
& & Sig. (2-tailed) &. & .020 \\
& N & 75 & 75 \\
& MC-R & Correlation Coefficient & $.269 *$ & 1.000 \\
& Sig. (2-tailed) & .020 &. \\
& N & 75 & 75 \\
\hline
\end{tabular}

Note. * Correlation is significant at the 0.05 level (2-tailed).

From the table we know that the significance of correlation between scores of MC-XY-T and MC-R-T is .020, and the correlation coefficient $\mathrm{p}$ is .269. Therefore we conclude that scores of MC-XY-T and MC-R-T are significantly correlated, which verifies our second hypopaper.

The third and last hypopaper is that scores of MC-XY-T and MC-R-T are respectively related to scores of reading proficiency. The following isTable 6 produced by SPSS. 
Table 6. Correlations between reading and MC-XY

\begin{tabular}{lllll}
\hline & & Reading & MC-XY \\
\hline Spearman's rho & Reading & Correlation Coefficient & 1.000 & .008 \\
& & Sig. (2-tailed) &. & .945 \\
& N & 75 & 75 \\
& MC-XY & Correlation Coefficient & .008 & 1.000 \\
& & Sig. (2-tailed) & .945 &. \\
& $\mathrm{~N}$ & 75 & 75 \\
\hline
\end{tabular}

We can draw from the table that the significance of correlation between scores of MC-XY-T and reading proficiency is .945, and the correlation coefficient $\mathrm{p}$ is .008, so we conclude scores of MC-XY-T and reading proficiency are not significantly correlated. One important reason due to this insignificance is possibly that MC-XY-T contains productive items to some extent.

Now we will examine the correlation between MC-R-T and reading proficiency. Below is Table 7 produced by SPSS.

Table 7. Correlations between reading and MC-R

\begin{tabular}{lllll}
\hline & & Reading & MC-R \\
\hline Spearman's rho & Reading & Correlation Coefficient & 1.000 & $.442^{* *}$ \\
& & Sig. (2-tailed) &. & .000 \\
& N & 75 & 75 \\
& MC-R & Correlation Coefficient & $.442^{* *}$ & 1.000 \\
& Sig. (2-tailed) & .000 &. \\
& N & 75 & 75 \\
\hline
\end{tabular}

Note. ${ }^{* *}$ Correlation is significant at the 0.01 level (2-tailed).

In this table, the significance of correlation between scores of MC-R-T and reading proficiency is .001, and the correlation coefficient $\mathrm{p}$ is .442. Accordingly we conclude that scores of MC-R-T and reading proficiency are significantly correlated.

Until now we have gained the results of our study in this paper:

1) Receptive metaphoric competence and reading comprehension are significantly correlated.

2) MC-XY-T and MC-R-T are significantly related with each other.

3) MC-XY-T and reading proficiency are not significantly correlated, which shows the students' sensibility of metaphors may be not so closely related with their reading proficiency.

4) MC-R-T and reading proficiency are significantly correlated.

However, as we can discover in this table, the correlate coefficient is not very high. There are several explanations for this moderate correlation.

First, these correlate coefficients are not large because we employed nonparametric test in the processing of data. As an uncontested fact, nonparametric test is not as efficient as the parametric test in explaining the correlation. This also contributes to the comparatively low correlation. Secondly the possible test error may also influence the result. The test of metaphoric competence is revised, though not originated by the author, a relatively inexperienced young teacher. Although careful procedures were adopted to prevent test errors, it is still possible for unexpected factors to appear and influence test results.

Nevertheless, the fact remains that scores of the receptive metaphoric competence test and its two components and the L2 reading proficiency scores are substantially correlated as shown in the above tables. It is practicable for us to make the statement that receptive metaphoric competence is somehow linked with second language reading proficiency.

\section{Conclusion and Implications}

Although metaphor has been studied for centuries, the results from those studies are limitedly applied into 
second or foreign language learning and teaching. In order to make clear the relationship between L2 proficiency and metaphoric competence, this paper studies the correlation between one aspect of L2 proficiency-reading proficiency and one part of metaphoric competence--receptive metaphoric competence, with a purpose to offer some implications for the future English education especially for teaching of reading in Chinese EFL environment.

From the data in this paper, we get the findings as the following:

1) Chinese L2 learners' receptive metaphoric competence is situated at the middle or low level. It is not developed sufficiently for L2 learners.

2) Receptive metaphoric competence is to some extent linked to reading proficiency. For L2 learners, the higher in reading proficiency, the better in metaphoric competence. Good language learners especially those who are skilled at L2 reading are inclined to be at higher level of metaphoric competence. Metaphoric competence, particularly receptive metaphoric competence is a significant factor to influence L2 reading proficiency.

3) Therefore, the importance of metaphoric competence, especially receptive metaphoric competence, or figurative competence in a broader sense, is supposed to be addressed with regard tothe implications in reading lessons. It is suggested that teachers pay more attention to students' development of figurative language as well as the training of their reading skills, and design suitable tasks to help students better understand metaphors from both the discourse and lexical levels, with the purpose to arouse their awareness and sensibility of metaphorical study.

In terms of lexical study, one of the difficulties for learners is polysemy and collocation, particularly those includes a lot of metaphorical expressions. Carter, R. and M. Michael(1988) support the teaching of metaphor sets for learners' vocabulary enlargement through associative bonding. This means that the lexical items in a metaphor set, for example, ARGUMENT IS WAR, can be taught in terms of associative bonding.Therefore it is suggested that teachers help students acquire the metaphorical meaning based on the literal meaning, especially with the facility of context.

Certainly there are some limitations in this research. The most prominent one was the limited number of test items and subjects. The availability of subjects was limited, but the author engaged as much as 75 subjects in the present study to get a satisfactory data. However, the more subjects would guarantee a better study result.

Due to the scarcity of the number of test items, the cultural aspects of metaphoric competence could not be fully examined. Concerned with MC-XY-T and MC-R-T, the test items were not enough. This type of test takes the pattern of conceptual metaphors and can investigate schemas and image schemas specific to Chinese L2 learners.

Meanwhile, the reading proficiency test and receptive metaphoric test were administered in different contexts. On one hand, reading proficiency test was taken more important and serious; hence it was administered in a quite uneasy test. If some testees behaved too nervously, the test results would be somewhat mistakable. On the other hand, the R-MC test was exercised in a more relaxed and less formal environment. Therefore there must be imbalance between these two tests at least to some degree.

Based on the previous limitations of the present study, some suggestions are proposed for future similar researches.

First, this study is mainly concerned with the correlation between receptive metaphoric competence and reading proficiency, nevertheless, there is still space for the future researches on other aspects of L2 proficiency, such as listening, writing or speaking, and their relationship with other aspects of metaphoric competence, like productive metaphoric competence. Since researches in this field and the application are limited in number, the author believes that we could do much more studies with reference to metaphor and metaphoric competence.

Second, this study did not focus on the factors which influence or determine the differences of the individual L2 learners in metaphoric competence, meanwhile, few previous studies on this topic examined the factors affecting metaphoric competence, therefore some future studies could and should be done to contribute to the analysis of the factors, especially the cultural factors, though it possibly is a tough task.

Third, the future study should involve as many testees as possible to promote the accuracy of the results. Besides, more test items are supposed to be added in future tests in order to make the aspects of metaphoric competence be tested thoroughly and fairly as well as improve the valid.

\section{Acknowledgements}

This work was supported in part by the Fundamental Research Funds for the Central Universities under Grant No. XDJK2014A002, the Humanity and Social Science Research Youth foundation of Southwest University 
under Grant No. SWU08111, and the Doctoral Fund of Southwest University under Grant No. SWU1110361.

\section{References}

Azuma, M. (2005). Metaphorical competence in an EFL context-the mental lexicon and metaphorical competence of Japanese EFL students. Tokyo: Toshindo Publishing.

Boers, F. (2000). Enhancing metaphoric awareness in specialized reading. English for Specific Purposes, 19, 137-147.

Cameron, L. (2003). Metaphor in educational discourse. London: Continuum.

Cameron, L., \& Low, G. (1999). Metaphor. Language Teaching, 32, 77-96. http://dx.doi.org/10.1017/S0261 444800013781

Carter, R., \& Michael, M. (1988). Vocabulary and language teaching. London and NewYork: Longman.

Connolly, T. G., \& Sluckin, W. (1953). An introduction to statistics for the social sciences. London: Cleaver-Hume Press.

Danesi, M. (1992). Metaphor and classroom second language learning. Romance Languages Annual, 3, 189-194.

Deignan, A., Gabrys, D., \& Solska, A. (1997). Teaching English metaphors using cross-linguistic awareness-raising activities. ELTJournal, 51, 352-360.

Gardner, H. (1974). Metaphors and modalities: How children project polar adjectives onto diverse domains. Child Development, 45, 84-91.http://dx.doi.org/10.2307/1127753

Gardner, H., \& Winner, E. (1979). The implications for humanistic disciplines: Development of metaphoric competence. In S. Sacks (Ed.), On metaphor. Chicago: University of Chicago Press.

Gibbs, R. W. (1980). Spilling the beans on understanding and memory for idioms in conversation. Memory \& Cognition, 8, 149-156. http://dx.doi.org/10.3758/BF03213418

Harmer, J. (2003). The practice of English language teaching, 3rd. New York/Beijing: Pearson Education/World Affairs Press.

Johnson, J., \& Rosano, T. (1993). Relation of cognitive style to metaphor interpretation and second language proficiency. Applied Psycholinguistics, 14, 159-159. http://dx.doi.org/10.1017/S014271640000953X

Lakoff, G., \& Johnson, M. (1980). Metaphors we live by. Chicago: University of Chicago Press.

Littlemore, J. (2001a). Metaphoric competence: A language learning strength of students with a holistic cognitive style. TESOL Quarterly, 35, 459-491. http://dx.doi.org/10.2307/3588031

Littlemore, J. (2001b). Metaphoric intelligence and foreign language learning. Humanising Language Learning, 3, 10-101. http://dx.doi.org/10.1017/S014271640000953X

Low, G. (1988). On teaching metaphor. Applied Linguistics, 9, 125-147. http://dx.doi.org/10.1093/applin/9.2.125

Ortony, A. (1980a). Some psycholinguistic aspects of metaphor. In R. P. Honeck, \& R. R. Hoffman (Eds.), Cognition and figurative language (pp. 69-83). New Jersey: Lawrence Erlbaum.

Ortony, A. (1980b). Metaphor. In B. C. Spiro, \& W. F. Bewer (Eds.), Theoretical issues in reading comprehension (pp. 349-365). New Jersey: Lawrence Erlbaum.

Pollio, H. R., \& Smith, M. K. (1980). Metaphoric competence and complex human problem solving. In R. P. Honeck, \& R. P. Bums (Eds.), Cognition and figurative language (pp. 365-392). New Jersey: Lawrence Erlbaum.

Richards, A. (1965). The philosophy of rhetoric. New York: Oxford University Press.

Winner, E., Rosenstiel, A. K., \& Gardner, H. (1976). The development of metaphoric understanding. Developmental Psychology, 12, 289.

\section{Appendix}

\section{Items for receptive metaphoric competence test}

1. Please make two different sentences for each word, one including literal meaning, while the other including metaphorical meaning. You are required to make 12 sentecnes with the following six words

Example:

The adjective hard: 
Literal: The object on the table is a hard stone.

Metaphorical: Mike Tyson's muscles are hard steel.

1) The adjective bright:

Literal:

Metaphorical:

2) The adjective dark:

Literal:

Metaphorical:

3) The adjective grey:

Literal:

Metaphorical:

4) The adjective high:

Literal:

Metaphorical:

5) The adjective weak:

Literal:

Metaphorical:

6) The adjective wild:

Literal:

Metaphorical:

2. Please read the following passages and write after each passage the meaning of the underlined expressions, one including literal meaning, while the other including metaphorical meaning. Both English and Chinese for your answers are acceptable.

1) Target sentence/idiom: to let the cat out of the bag

a) "Mr. Brown's fed up with the cat killing his birds. He says he's going to put it in a bag and drown it," she said. "How awful!" John replied. "When he is not looking, you'll have tolet the cat out of the bag."

Meaning:

b) "I told Jane everything." Mickey said.

"I told you she can't keep a secret." Ruth said, "She always lets the cat out of the bag."

Meaning:

2) Target sentence/idiom: A little pot is soon hot

a) The head chef and assistant were in the kitchen with the boss's daughter. She was only five years old. She wanted to be a chef when she was older. She was about to grab a pot from the cooker, when the chef exclaimed, "A little pot is soon hot."

Meaning:

b) Harry hadn't seen his mate, frank's sister Kerry in years. He had been away at university. The last time he saw her she was a spoilt, cheeky 14 years old. She was 18 years old now. Harry thought Kerry looked gorgeous now. Frank realized this and smilingly nudged Harry and said, "A little pot is soon hot!"

Meaning:

3) Target sentence/idiom: The rotten apple injures its neighbors.

a) Sally and Tom had a beautiful garden. At the bottom of the garden there was an apple tree. On Sunday afternoon they picked all the apples and put them in the box. However, a rotten apple had been put in by mistake and it turned all the others bad. When Sally realized this, she said, "The rotten apple injures its neighbors."

Meaning:

b) "Somerville used to be such a nice area," said Anne. 
"Yes," agreed Cheryl, "but once a few bad families started to move in, the area got a really bad reputation."

"The problem is that the rotten apple injures its neighbors." replied Anne.

Meaning:

4) Target sentence/idiom: a pain in the neck

a) I had just bought a new sweater but the collar was very tight. So much so that it was giving me such a pain in the neck. My whole neck was bruised.

Meaning:

b) One of our teachers cannot ever speak English, so that, as we don't grasp any of the main ideas, getting the essay done is such a pain in the neck, since we have no notes.

Meaning:

5) Target sentence/idiom: to be off one's head

a) Dave and Graham are gardeners, and were discussing headgear. Graham said, "I don't want to wear a hat to the garden this year."

"But I wore it last year, and it's a tradition. We've been wearing that hat for almost thirty years."

"I'll make someone else wear it this year. It's itchy." "Well, as long as it can be off my head."

Meaning:

b) Bob and Janies were discussing Johnny's birthday plans.

"So, we'll do a pub crawlthen. How many pubs are there in London?" said Bob. "Too many tocount, " replied James. "Oh well, the main thing Johnny wants for his birthday is to be off his head."

Meaning:

6) Target sentence/idiom: to count heads

a) At the meeting, Sarah had to fix the catering. She lost the files of RSVPs. She didn't know many people were coming. She was struck. Jane joked and told her to "count heads."

Meaning:

b) Sam and James were discussing their love lives. Both had ended their respective relationships. They were feeling quite down. They noticed some good-looking girls on the side table. The girl winked at them and beckoned them over. Sam cheered up and told James to "count heads" in their lives at the moment.

Meaning:

7) Target sentence/idiom: to hold one's head up high

a) Sally loved to watch all the horsed go down her street. They looked so majestic and elegant but she could not work out why. When she told her friend, she said, "It is the way they held their heads up high.

Meaning:

b) Everyone was talking about incident that had happened down at the sea. A sudden wave had appeared nearly drowned a boy. However, luckily a man had jumped in and saved him. "Well," Gloria, "that man can hold his head UP high."

Meaning:

8) Target sentence/idiom: to stand in someone's way

a) Sophie was at the station in a hurry to catch a train. On that way the station was extremely busy. There were too many people about and every time she changed direction she bumped into people standing in her way, so as a result she was delayed and consequently missed the train.

Meaning:

b) The mayor was preparing his campaign speech for the forthcoming election. He was running against his rival Mr. Thompson who stood in his way on the road to reelection because he was becoming more popular since proposing to clean up the city.

Meaning:

9) Target sentence/idiom: wake not a sleeping lion 
a) In the zoo the warden explained how aggravated and violent the animals get when provoked. He addressed the visitors "Wake not a sleeping lion."

Meaning:

b) She had had a lot on her mind lately. Especially at home, and school only made things worse. He knew he had offended her but desperately needed to speak to her. His friend advised him saying, "Wake not a sleeping lion."

Meaning:

10) Target sentence/idiom: Fish beginstostinkat the head.

a) Laura, Sally and Peggy were preparing a meal.

"Is the fish still alright to eat for dinner?"

"Smell it to see. If you smell the head it is the best way."

"Fish begins to stink at the head."

Meaning:

b) The four men stood huddled together talking quietly.

"There is a rat in the system somewhere.

"Private information is being leaked to other companies."

"I don't trust the boss myself. He may not be involved, but he is a part of the problem." "Fish begins to stink at the head."

Meaning:

11) Target sentence/idiom: You cannot eat your cake and have your cake.

a) Johnny and his mother were organizing his birthday party. They were in the supermarket, and Johnny pointed to a large chocolate cake.

"There'll be enough for me and all my friends," he said.

"You can't have any cake, Johnny," said his mother reproachfully.

"Why not?" cried Johnny indignantly.

"You cannot eat your cake and have your cake," she said.

Meaning:

b) President Clinton was talking to his aids, and asked if they could end world hunger, poverty and war before the New Year.

"Of course not, Mr. President," said one side, surprised by the question.

"Why ever not?" asked Clinton, confused.

"You cannot ear your cake and have your cake."

Meaning:

\section{Copyrights}

Copyright for this article is retained by the author(s), with first publication rights granted to the journal.

This is an open-access article distributed under the terms and conditions of the Creative Commons Attribution license (http://creativecommons.org/licenses/by/3.0/). 